Article

\title{
Bifunctional Cation Exchange Resin Having Both Phosphonate and Sulfonate Groups Derived from Macroreticular Poly( ( -bromobutylstyrene-co-divinylbenzene)
}

\author{
Kenji OKADA, Naomi JO, and Akinori JYO \\ Department of Applied Chemistry and Biochemistry, Faculty of Engineering, Kumamoto University, Kumamoto \\ 860-8555, Japan
}

(Manuscript submitted February 15, 2002; accepted April 21, 2003)

\begin{abstract}
A bifunctional cation exchange resin (R4PS) having both phosphonate and sulfonate groups was derived from macroreticular poly( $\omega$-bromobutylstyrene-co-divinylbenzene). Phosphorus and sulfur contents of R4PS were 2.2 and $2.5 \mathrm{mmol} / \mathrm{g}$, respectively, and its acid capacity was $6.6 \mathrm{meq} / \mathrm{g}$. R4PS exhibits the characteristic metal ion selectivity, which is different from that of each monofunctional resin containing phosphonate or sulfonate group alone. In the strongly acidic region below $\mathrm{pH} 2$, R4PS has higher capacities for uptake of $\mathrm{Fe}(\mathrm{III})$ than does a corresponding monofunctional phosphonate resin. In column-mode uptake of $\mathrm{Fe}$ (III) from strongly acidic feeds, R4PS exhibited excellent kinetic performances because of its high swelling in the wide $\mathrm{pH}$ range.
\end{abstract}

\section{Introduction}

Phosphonate resins exhibit the high selectivity to hard Lewis acid cations, such as, $\mathrm{Fe}(\mathrm{III}), \mathrm{U}(\mathrm{VI})$ and $\mathrm{Zr}(\mathrm{IV})$.[1] Since these high valence metal ions tend to precipitate as hydroxides, their adsorption operation by phosphonate resins must be conducted under strongly acidic media, which are not suitable for high swelling of resins having weakly acidic sites like oxy-acid groups of phosphorus. Incomplete swelling of resins leads to poor kinetics and low capacities in uptake of metal ions. To overcome this difficulty in phosphonate resins, Alexandratos et al. have proposed bifunctional resins having both phosphonate and sulfonate groups.[2-4] In almost the same period, Tomoi et al. [5] reported thermally stable anion exchange resins derived from poly( $\omega$-bromobutylstyrene-co-divinylbenzene) (R4). This spacer chain type copolymer R4 is attractive as a new type of the precursor for preparation of various bifunctional resins, since one kind of functional group can be introduced into the terminal of n-butyl chains and the other to phenyl group of R4. This paper describes preparation and characterization of a bifunctional resin having both phosphonate and
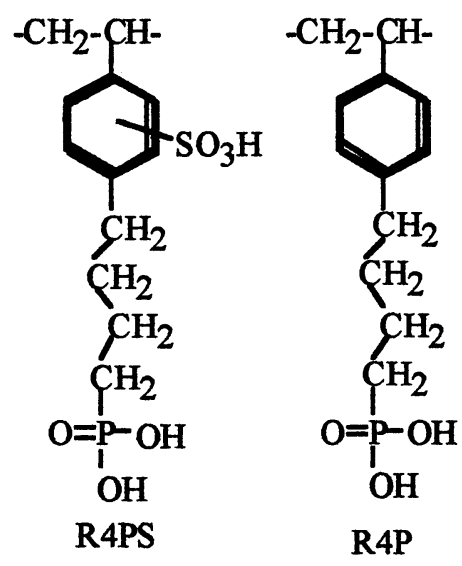
sulfonate groups (R4PS). Properties of R4SP were also compared with those of the monofunctional phosphonate resin R4P. 


\section{Experimental}

\subsection{Materials}

The monomers, $\omega$-bromobutylstyrene (BBS) and divinylbenzene (DVB) (81\%), were kindly provided by Mitsubishi Chemical Co. (Tokyo, Japan). To remove inhibitors, BBS was passed through a silica-gel (Waco-gel C 200) column, and DVB was shaken with $1 \mathrm{M}\left(\mathrm{M}=\mathrm{mol} \mathrm{dm}{ }^{-3}\right) \mathrm{NaOH}$ and then washed with water. DVB thus treated was dried on anhydrous sodium sulfate before use. Other reagents were of guaranteed grade, unless otherwise specified.

\subsection{Preparation of resins}

BBS and DVB were polymerized in the presence of the porogen $n$-heptane according to a conventional suspension polymerization technique. The degree of the crosslinking was $10 \mathrm{~mol} \%$ of DVB, and volume ratio of the porogen to the monomer mixture was 0.80 . The resulting copolymer beads (R4) with diameter of $246-496 \mu \mathrm{m}$ were collected by meshing, and used in further study. Its BET specific surface area and bromine content were $25 \mathrm{~m}^{2} / \mathrm{g}$ and $2.8 \mathrm{mmol} / \mathrm{g}$, respectively. The bifunctional resin (R4SP) and monofunctional one (R4P) were prepared according to a method almost the same as one reported by Alexandratos et al. [2] The resulting R4PS and R4P were further treated with refluxed aqueous $\mathrm{NaOH}(1 \mathrm{M})$ for $24 \mathrm{~h}$ and again with refluxed conc. hydrochloric acid for $24 \mathrm{~h}$ for the purpose of complete hydrolysis and conditioning as well. After washing with water, they were air-dried and then dried in vacuum at $40{ }^{\circ} \mathrm{C}$ for more than $24 \mathrm{~h}$. Both resins were used in the $\mathrm{H}^{+}$form, unless otherwise noted, and their phosphorus contents and acid capacities were measured as described.[6] Sulfur content of R4PS was measured by ion chromatography after the combustion of a R4PS sample as described.[7]

\subsection{Studies on uptake of metal ions}

Distribution ratios $(D)$ of metal ions and capacities for uptake of metal ions were measured by batchwise methods as reported in detail elsewhere.[6] Behavior of both resins in column mode adsorption and elution of $\mathrm{Fe}$ (III) was examined according to the reported method.[6] Detailed experimental conditions will be given with results in later sections.

\section{Results and discussion}

\subsection{Properties of resins.}

Table 1 shows results of chemical analyses, acid capacities, and dry and wet volumes of R4PS and R4P. Acid capacities of both resins are nearly equal to or slightly less than ones calculated from their analytical data. Wet volumes of R4PS equilibrated with water and $1 \mathrm{M} \mathrm{HCl}$ are larger than those of R4P, indicating that R4PS highly swells even in strongly acidic media as anticipated. Equilibration with $1 \mathrm{M} \mathrm{NaOH}$ converts both resins into the $\mathrm{Na}^{+}$form, resulting in a marked increase in their wet volumes. The difference in wet volumes of R4PS between $\mathrm{Na}^{+}$and $\mathrm{H}^{+}$forms is less than that of R4P. This is also one of advantages of R4SP, since the resin Table 1 Properties of R4PS and R4P

\begin{tabular}{|c|c|c|c|c|c|c|c|}
\hline \multirow[t]{2}{*}{ Resin } & \multirow{2}{*}{$\begin{array}{c}\text { Phosphorus } \\
\text { content } \\
(\mathrm{mmol} / \mathrm{g})\end{array}$} & \multirow{2}{*}{$\begin{array}{l}\text { Sulfur } \\
\text { content } \\
(\mathrm{mmol} / \mathrm{g})\end{array}$} & \multirow{2}{*}{$\begin{array}{c}\text { Acid } \\
\text { capacity } \\
\text { (meg/g) }\end{array}$} & \multicolumn{4}{|c|}{$\begin{array}{l}\text { Volume } \\
\left(\mathrm{cm}^{3} / \mathrm{g}\right)\end{array}$} \\
\hline & & & & dry & IMNaOH & water & TMHCI \\
\hline R4P & 2.2 & 2.5 & 6.6 & 1.92 & 3.55 & 3.14 & 3.10 \\
\hline R4P & 2.7 & - & 5.3 & 2.40 & 3.83 & 2.72 & 2.71 \\
\hline
\end{tabular}
with small change in wet volumes in wide $\mathrm{pH}$ range is preferable in column-mode use.

\subsection{Distribution of metal ions}

The distribution study was conducted to evaluate the metal ion selectivity sequences of R4PS and 
$\mathrm{R} 4 \mathrm{P}$ by keeping the equivalence ratio $E_{M} / E_{H}$ is much less than unity; here, $E_{H}$ and $E_{M}$ are an initial equivalences of hydrogen ion as counterion in each resin $(0.04 \mathrm{~g})$ and that of the metal ion in solutions $(0.0001 \mathrm{M}, 25 \mathrm{~mL})$, respectively. Since $E_{H}$ is much greater than $E_{M}, E_{H}$ can be regarded as constant, the following equation (i) holds so long as the distribution of metal ions occurs by the ion exchange mechanism:[1]

$$
\log D=\text { Constant }+n \cdot \mathrm{pH}
$$

Here, $n$ means a formal charge number of a given metal ion. For 12 kinds of metal ions, the equation (i) holds, and observed slopes were nearly equal to $n$ in the case of R4PS, whereas those were somewhat lower than $n$ in the case of R4P. From these linear relations, values of a half extraction $\mathrm{pH}\left(\mathrm{pH}_{1 / 2}\right)$ were calculated, and they are shown in Fig.1 along with values of sulfonate resin Diaion PK216 for comparison.[8] The bifunctional R4SP clearly exhibits the characteristic metal ion selectivity sequence different from those for both R4P and Diaion PK 216; the metal ion

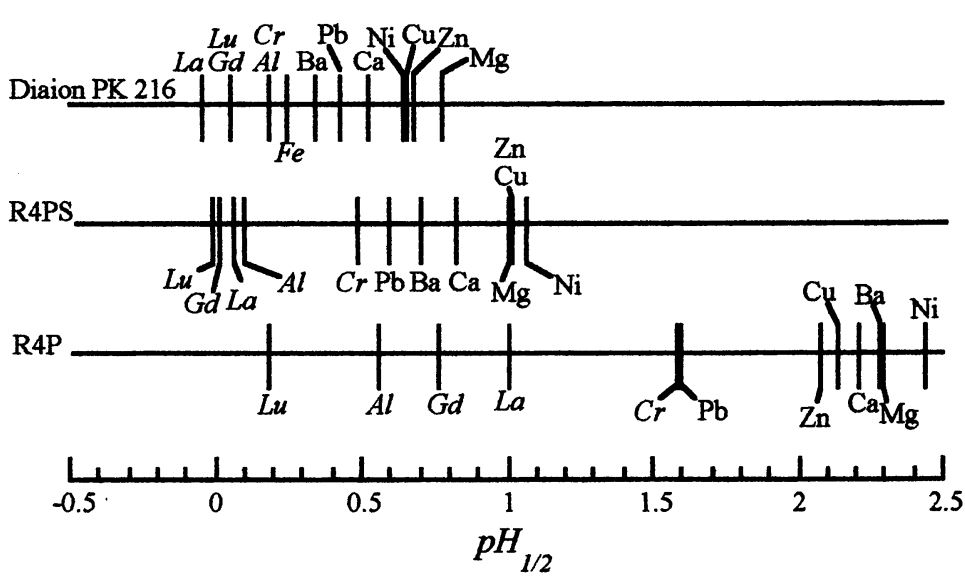

Fig. 1 Half extraction $\mathrm{pH}$ values of metal ions for three cation exchangers. Values for Diaion PK 216 were quoted from Ref. [8]. Experimental conditions: resin $0.04 \mathrm{~g}$, metal ion solution $0.0001 \mathrm{M}(25$ $\mathrm{cm}^{3}$ ). The $\mathrm{pH}$ of aqueous phases was adjusted with nitric acid. Roman and italic symbols mean divalent and trivalent cations, respectively.

selectivity sequence of R4SP seems to

be the convolution of those of sulfonate and phosphonate resins.

In the distribution of $\mathrm{Fe}$ (III) from nitric acid media into R4PS and R4P, $\log D$ vs. $\mathrm{pH}$ plots describe curves with minimum at $\mathrm{pH} c a$. -0.6 . This indicates that $\mathrm{Fe}(\mathrm{III})$ is distributed into the both resins through normal cation exchange and solvation extraction mechanisms as reported.[1] These results indicate that R4PS and R4P have the highest affinity to Fe(III) among the tested 13 kinds of metal ions different from the sulfonate resin Diaion PK216.[8]

\subsection{Capacities for uptake of metal ions}

Capacities for uptake of $\mathrm{Fe}(\mathrm{III})$ and $\mathrm{Pb}$ (II) as a function of $\mathrm{pH}$ were measured under conditions that the equivalence ratio $E_{M} / E_{H}$ is greater than unity opposed to the case of the distribution study. Figure 2 shows the results. The bifunctional R4PS takes up much more amount of both $\mathrm{Pb}$ (II) and $\mathrm{Fe}$ (III) than does the monofucntional R4P. These results suggest that sulfonate groups in R4PS assist the complexation of phosphonate groups giving enough free space for complexation of phosphate groups as a result of the higher swelling of R4PS. On the contrary, the majority of phosphonate groups in R4P can not work well under acidic conditions because of its lower swelling, in particular, in the $\mathrm{pH}$ region less than 2 . Iron(III) tends to form bulky multinuclear species under conditions that analytical

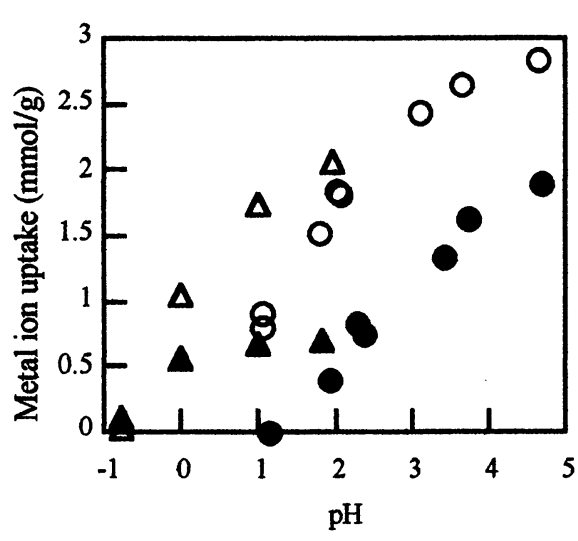

Fig. 2 Uptake of $\mathrm{Fe}(\mathrm{III})$ and $\mathrm{Pb}(\mathrm{II})$ as a function of $\mathrm{pH}$. R4PS: $\mathrm{O} \mathrm{Pb}(\mathrm{II}), \triangle$ $\mathrm{Fe}$ (III). R4P: $\mathrm{Pb}$ (II), $\Delta \mathrm{Fe}$ (III). Amount of resin $0.1 \mathrm{~g}$. Metal ion solutions $0.01 \mathrm{M}$ $\left(45 \mathrm{~cm}^{3}\right)$. The $\mathrm{pH}$ was adjusted with nitric acid, acetic acid, and/or sodium acetate. 
concentrations of $\mathrm{Fe}$ (III) are greater than $10^{-3.7} \mathrm{M}$ at pH $1 \sim 2$.[9] Thus, the effect of the low swelling becomes more marked in the adsorption of Fe(III). Indeed, uptake of Fe(III) by R4P between $\mathrm{pH} 0$ and 2 does not so markedly increase with an increase in $\mathrm{pH}$.

\subsection{Column-mode Adsorption and Elution of Fe(III)}

Figure 3 illustratively shows breakthrough profiles of $\mathrm{Fe}$ (III) during the column-mode adsorption of $\mathrm{Fe}$ (III), and numerical data are summarized in Table 2. As judged from Fig. 3 and Table 2, R4PS is also superior to R4P in performances of the column-mode adsorption of $\mathrm{Fe}(\mathrm{III})$; breakthrough and column capacities of R4PS for $\mathrm{Fe}$ (III) are much greater than those of R4P. The adsorbed $\mathrm{Fe}$ (III) was quantitatively eluted with aqueous $6 \mathrm{M}$ $\mathrm{HCl}$, and their repeated use was possible. As judged from Table 2, column capacity of R4PS for $\mathrm{Fe}$ (III) corresponds to more than 90 percents of its acid capacity, whereas that of R4P is less than a half the acid capacity of R4P.

As demonstrated in this work, macroreticular

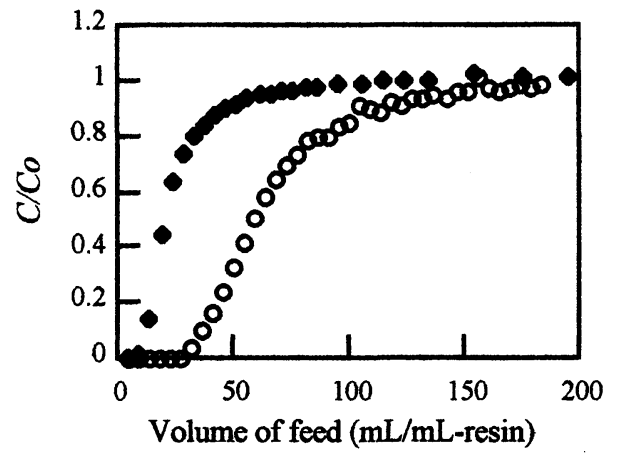

Fig. 3 Breakthrough profiles of $\mathrm{Fe}$ (III) in the column-mode adsorption of $\mathrm{Fe}$ (III). $O$ R4PS (run1) and $\bullet$ R4P (run 1).

Column (i.d. $6 \mathrm{~mm}$ ): $1 \mathrm{~cm}^{3}$ of each wet resin in hydrogen ion form.

Feed: ca. $0.01 \mathrm{M}$ ferric nitrate in $0.1 \mathrm{M}$ nitric acid, flow rate, $10 \mathrm{~h}^{-1}$ in $S V$.

Refer to Table 2 for other conditions.

poly ( $\omega$-bromobutylstyrene-co-divinylbenzene) is a promising precursor for various kinds of bifucntional chelating resins, which have high performances in uptake of metal ions from strongly acidic solutions.

Table 2 Column mode adsorption and elution of Fe(III)

\begin{tabular}{|c|c|c|c|c|c|c|c|c|}
\hline \multirow[t]{2}{*}{ Resin } & \multirow[t]{2}{*}{ Run } & \multicolumn{3}{|c|}{ Conditions for feed ${ }^{a}$} & \multirow{2}{*}{$\begin{array}{l}\text { Breakthrough } \\
\text { point }^{\mathrm{b})} \\
\text { (Bed volumes) }\end{array}$} & \multirow{2}{*}{$\begin{array}{l}\text { Breakthrough } \\
\text { capacity } \\
\left(\mathrm{mmol} / \mathrm{cm}^{3}-\mathrm{R}\right)^{\mathrm{a})}\end{array}$} & \multirow{2}{*}{$\begin{array}{c}\text { Column } \\
\text { capacity } \\
\left(\mathrm{mmol} / \mathrm{cm}^{3}-\mathrm{R}\right)\end{array}$} & \multirow{2}{*}{$\begin{array}{c}\text { Amount } \\
\text { eluted } \\
\left(\mathrm{mmol} / \mathrm{cm}^{3}-\mathrm{R}\right)\end{array}$} \\
\hline & & $\begin{array}{c}C_{o} \\
(\mathrm{mM})\end{array}$ & $\mathrm{pH}$ & $\begin{array}{c}\text { Volume } \\
\text { (Bed volumes) }\end{array}$ & & & & \\
\hline \multirow[t]{2}{*}{ R4PS } & 1 & 9.0 & 1.04 & 183 & 33 & $0.30(0.94)^{c}$ & $0.62(1.9)$ & $0.63(2.0)$ \\
\hline & 2 & 11 & 1.05 & 188 & 29 & $0.30(0.94)$ & $0.72(2.2)$ & $0.68(2.1)$ \\
\hline \multirow[t]{2}{*}{ R4P } & 1 & 10 & 1.05 & 195 & 11 & $0.11(0.30)$ & $0.26(0.71)$ & $0.28(0.76)$ \\
\hline & 2 & 9.5 & 1.04 & 191 & 12 & $0.11(0.30)$ & $0.26(0.71)$ & $0.27(0.73)$ \\
\hline
\end{tabular}

a) Flow rates of feeds and eluent $(6 \mathrm{M} \mathrm{HCl})$ were $10 \mathrm{~h}^{-1}$ in space velocity. ${ }^{\text {b) }} 5 \%$ breakthrough point and capacity. ${ }^{\mathrm{c}}$ Figures in parentheses are quantities in mmol/g-dry resin. Refer to Fig. 3 for other conditions.

\section{References}

1) K. Yamabe, T. Thara, and A. Jyo, Sep. Sci. Technol., 36, 3511-3528(2001).

2) A. W. Trochimczuk and S. D. Alexandratos, J. Appl. Polym. Sci., 52, 1273-1277(1994).

3) S. D. Alexadratos and S. Natesan, Eur. Polym. J., 35, 431-436(1999).

4) S. D. Smith and S. Alexandratos, Solvent Ext. Ion Exchange, 18, 779-807 (2000).

5) M. Tomoi, K. Yamagchi, R. Ando, Y. Kantake, Y. Aosaki, and H. Kubota, J. Appl. Polym. Sci., 64, 11611167(1997).

6) X. Zhu and A. Jyo, J. Ion Exchange, 11, 68-78(2001).

7) H. Egawa, A. Jyo, and C. Chen, Nihon Kagaku Kaishi,1994, 440-449.

8) A. Jyo and X. Zhu, "Environmental Science Research, Vol. 55, Chemistry for the Protection of Environment 3" (Eds. L. Pawlowsky, M.A. Gonzales, M. R. Dudzinska, and W. L. Lacy), Plenum Press, New York (1998), pp.135-142.

9) A Ringbom, "Complexation in Analytical Chemistry", John Wiley \& Sons, New York (1963), pp. 31-35 